Work, employment and society

\title{
Working retirees in Europe: individual and societal determinants
}

\section{Ellen Dingemans}

Netherlands Interdisciplinary Demographic Institute (NIDI-KNAW \& University of Groningen), the Netherlands; University Medical Center Groningen (UMCG-RUG), the Netherlands

\section{Kène Henkens}

Netherlands Interdisciplinary Demographic Institute (NIDI-KNAW \& University of Groningen), the Netherlands; University Medical Center Groningen (UMCG-RUG), the Netherlands;

University of Amsterdam, the Netherlands

\section{Hanna van Solinge}

Netherlands Interdisciplinary Demographic Institute (NIDI-KNAW \& University of Groningen), the Netherlands

\begin{abstract}
One of the solutions that could be used to resource the needs of ageing populations is the encouragement of individuals to extend working lives beyond retirement, often referred to as 'bridge employment'. Although previous studies provide important insights into individual determinants of bridge employment, there is scant research on the extent to which differences across countries and between genders exist and how these might be explained by economic and societal differences in the pension context. The determinants of participation in bridge employment are investigated among male and female retirees in 16 European countries. Multilevel models are estimated based on data from the Survey of Health, Ageing and Retirement in Europe project. It was found that where there is high expenditure on pensions there is a lower likelihood of retirees participating in bridge jobs, while strong norms that support working past retirement are positively associated with bridge employment.
\end{abstract}

\section{Keywords}

bridge employment, gender, multilevel logit analysis, pensions, retirement

\section{Corresponding author:}

Ellen Dingemans, Netherlands Interdisciplinary Demographic Institute, P.O. Box II650, NL-2502 AR The Hague, the Netherlands.

Email: dingemans@nidi.nl 


\section{Introduction}

Retirement arrangements emerged at the turn of the 19th to 20th century and have been dynamic in their form and meaning ever since. Following a period in which many workers enjoyed the prospect of early retirement, the prospect of an ageing population has put the topic of extending working life high on the policy agenda (Van Dalen et al., 2010). Many modern societies are confronted with unprecedented demographic changes, such as declines in fertility and mortality (Bongaarts, 2004), which will have severe consequences for the age structure of countries and the composition of the workforce. A relatively new group in the workforce consists of retirees who continue in paid work after retirement in so-called 'bridge jobs' (Feldman, 1994; Shultz, 2003). The participation of this group in paid labour is seen as one of the solutions to the consequences of an ageing population (Bongaarts, 2004; Maestas and Zissimopoulos, 2010).

The increasing popularity of bridge employment brings with it a need to identify its specific determinants. To date, economists and psychologists in particular have focused on individual level factors related to the decision to continue working after retirement (Cahill et al., 2006; Kim and Feldman, 2000; Wang et al., 2008). Societal factors have received only very limited attention so far (Beehr and Bennett, 2015), while the power of these factors has become particularly relevant, given the changing pension landscapes in modern societies. One exception is the cross-national study by Brunello and Langella (2012), which found that exogenous increases in minimum retirement age differentially affect retirement and bridge employment transitions across various European countries. Unfortunately, this study focused exclusively on the work-toretirement trajectories of men, and it is debatable whether explanatory models of bridge employment are the same for men and women (Beehr and Bennett, 2015). Therefore, the two following research questions are investigated in this study: (i) what determines bridge employment among male and female retirees in Europe?; and (ii) to what extent are the characteristics of the pension context important in explaining variation across countries?

The aim of this research is to contribute to the existing literature on bridge employment in three ways. First, our study is among the first to adopt a cross-national perspective on bridge employment. Most of the previous studies on the determinants of bridge employment are country-specific case studies. While these studies have been conducted mainly in the United States, the situation in European countries has recently started to receive some attention (e.g. Dingemans et al., 2015; Hochfellner, 2013). However, it is hard to compare results from different single-country studies because their definitions, conceptualizations and operationalizations of the bridge employment concept differ so widely. Thus, we aim to provide descriptive information about the variability in bridge employment across European countries and how it differs between men and women using harmonized data from 16 European countries.

Second, we attempt to explain the variation in bridge employment across countries by employing a multilevel approach to explore simultaneously the individual- and societallevel factors that may affect bridge employment. Two aspects of the country-specific context are deemed to be particularly important in this respect, namely the financial 
generosity of the pension system (Radl, 2013) and normative ideas about work and retirement (Liefbroer and Billari, 2010). By incorporating these factors into the explanatory model, we aim to test the expectation put forward by Zhan and Wang (2015) that both the economic and the social aspects of the pension context are important determinants of bridge employment.

Third, at the individual level, we investigate how the standing in the social hierarchy as well as marital status and informal caregiving activities affect participation in bridge employment. Previous studies on retirement decision-making have stressed that such explanatory models differ by gender (Damman, 2014; Pleau, 2010), but this assumption has hardly been investigated in respect of bridge employment (Pleau, 2010). Therefore, the approach of Beehr and Bennett (2015) is followed, who argue that 'both main effects and interaction effects need to be examined to truly understand the impact that gender has on retirement' (p. 6). Specifically, we examine whether marital status and participation in informal caregiving are differentially related to the bridge employment of men and women (Pleau, 2010).

For the current study, data are used from the Survey of Health, Ageing and Retirement in Europe (SHARE) project, which includes information on employment and retirement trajectories in 16 European countries. The definition of bridge employment proposed in the current study is slightly different from that regularly used in the United States (Gobeski and Beehr, 2009; Wang et al., 2008), where bridge employment is often defined as participation in a paid job after exit from a full-time career job with at least 10 years of tenure (Feldman, 1994). This definition would be problematic in several European countries because part-time employment is relatively common in all stages of the work career, especially among women (Eurofound, 2011). Therefore, we define bridge employment as the participation in paid work by those who receive a pension income (Dingemans et al., 2015; Parry and Bown Wilson, 2014).

\section{Theoretical framework}

Following Beehr and Bennett (2015) and Zhan and Wang (2015), it is assumed that participation in bridge employment can be explained by both individual-level and societallevel factors. This assumption relies strongly on sociological theory in which the social environment takes a central place in explaining individual behaviour. For instance, Giddens (1984) has emphasized the importance of social embeddedness in his theory of structuration. Giddens states that social scientists study 'neither the experience of the individual actor, nor the existence of any form of societal totality, but social practices ordered across space and time' (p. 2). In other words, behaviour is not the result of isolated individual decision-making or pure social determinism, but results from a combination of both. Similarly, a key premise in life course theory is that life transitions do not occur in isolation but are rather shaped by various influences from the social context (Settersten, 2003). This may be work-related influences, family-related aspects or broader societal characteristics that may form opportunities and constraints guiding individual behaviour. Below, we elaborate on how individuals' standing in social hierarchy, family-related influences and gender aspects, and societal characteristics may explain participation in bridge employment. 


\section{Standing in the social hierarchy}

Socioeconomic characteristics of individuals are deemed to be important stratification markers in explaining labour force participation, such as bridge employment (Dingemans et al., 2015). Depending on their standing in the social hierarchy, various subgroups of older adults may differ in their access to valuable resources that may enable or constrain participation in bridge jobs. First, from both the supply-side and demand-side perspective, it can be assumed that educational attainment - as a proxy for the level of human capital - positively relates to participation in bridge employment (Hypothesis 1). Highly educated individuals are most likely to be committed to the work role and be intrinsically motivated to continue working (Kalmijn and Kraaykamp, 2007). At the same time, they may be particularly attractive to employers offering bridge jobs because of their high level of human capital (Komp et al., 2010; Oude Mulders et al., 2014).

Second, the pension resources older adults receive may be of importance to the decision about bridge employment (Kantarci, 2012). In general, economic reasoning leads to the expectation that greater financial resources diminish the necessity of paid work to foresee in basic needs (Hypothesis 2). Third, a certain level of health is a prerequisite for participation in the labour force. Healthy older workers may be intrinsically motivated to remain active in old age, while at the same time having more opportunities than their unhealthy counterparts to find a suitable bridge job because they are not hindered by health-related limitations (Adams and Rau, 2004). Therefore, it may be expected that those in good health may be particularly likely to work in bridge jobs compared to those who suffer from health problems (Hypothesis 3).

\section{Family domain}

The retirement transition is deeply entwined with factors in the family domain and this may have consequences for the decision-making process on bridge employment as well (Komp et al., 2010; Pleau, 2010). Marital history may relate to work and retirement decisions via financial and social mechanisms (Damman, 2014). For instance, older adults who have been divorced during their life courses are assumed to be economically vulnerable in retirement (Damman, 2014; Pleau, 2010). More broadly, retirees without a partner cannot pool their resources and costs with a working spouse. In addition, retirees may opt to work past retirement for social reasons if they do not have a partner at home who could substitute the missing social interaction with colleagues (Damman et al., 2015). In this vein, those retirees who are divorced, widowed, or who have never been married may be particularly likely to work in bridge jobs compared to their married counterparts (Hypothesis 4).

Within the family domain, productive roles other than paid work roles are to be fulfilled. With regard to the provision of informal care, including the care for grandchildren, it has been argued that the likelihood of participating in bridge jobs is lowered in the case of such activities. The assumption is that the provision of care might limit the time that can be devoted to paid work (Carr and Kail, 2012; Komp et al., 2010). Based on a resources perspective (Wang, 2007), another mechanism for this negative relationship is that the limited number of social contacts in the case of caregiving reduces the level of 
social capital that is available to facilitate reintegration into the labour force after retirement (Carr and Kail, 2012). We therefore propose that informal caregiving for other adults or for grandchildren limits the likelihood of participation in bridge employment (Hypothesis 5).

\section{The role of gender}

Another well-known indicator of bridge employment is gender, with men being more likely to work in bridge jobs than women (Kim and De Vaney, 2005; Maestas, 2010). Based on social role theory, it can be derived that the relationship between gender and bridge employment may be influenced by the social roles men and women play in society (Eagly et al., 2000). More specifically, following the gendered model of labour division, it is argued that women are often dependent on economic protection from their husband both throughout their life course and in retirement (Pienta and Hayward, 2002; Pleau, 2010; Szinovacz and DeViney, 2000). This is found to have detrimental economic consequences for women in the case of marital disruption (Szinovacz and DeViney, 2000). Divorce may thus particularly motivate women to participate in bridge employment. Also, among other single women (widowed or never married), bridge employment may be particularly likely. Women, more than men, are expected to attach particular importance to personal relationships and relational attributes of work (Konrad et al., 2000). Together these assumptions lead to the expectation that retired women without a partner are particularly likely to work in bridge jobs compared to their male counterparts (Hypothesis 6).

Moreover, the gendered model of labour division points to gender-specific variation in the extent to which caregiving activities compete with paid employment. However, when it comes to the division of caregiving tasks in retirement, the direction of the relationship is less clear. Following Raymo and Sweeney (2006), it can be expected that women, as primary caregivers, are specifically likely to experience work-family conflict and therefore withdraw from work. On the other hand, the 'life course experience' of women who balance work and family demands may have equipped them with skills to balance work and care activities successfully after retirement as well, a capability that is less likely to be widespread among men who, as primary breadwinners, are mainly focused on paid employment throughout the course of their lives.

\section{Societal characteristics}

While it is often emphasized that differences in pension contexts across countries may have implications for the retirement trajectories that older adults take, the societal factors that relate to bridge employment are still largely unknown (Schalk and Desmette, 2015; Zhan and Wang, 2015). However, it is recognized that the specific interplay between economic factors and social norms has important consequences for decisions in the work and retirement domain (Lindbeck et al., 1999; Zhan and Wang, 2015).

Following Radl (2013), we postulate that cross-national differences in pension contexts create different incentive structures to work post-retirement. An important societal factor that may impose constraints on participation in paid work after retirement is the 
generosity of the pension system. Economic models predict that the more financial resources are available, the less likely older adults are to work past retirement (Hypothesis 7), simply because there is no financial necessity to do so (Feldman and Beehr, 2011). Regardless of the individual level of income, it can be argued that in a less generous pension context, bridge employment may be a common behaviour in retirement as a means to supplement pension income. It may even become an additional pillar in the construction of a retirement income, besides the three traditional pillars of public, occupational and private pensions (Bowman, 2014; Larsen and Pedersen, 2013).

At the same time, societal normative signs that promote the prolonged employment of older adults may also influence the likelihood of working after retirement. Liefbroer and Billari (2010) define a social norm as 'an expectation about acceptable behaviour that is shared by a group of people' (p. 290) and they argue that social norms are not something of the past but are still shaping individual behaviour in today's post-industrial and individualized societies. Life course theory suggests that the sequencing and timing of certain life events, such as the exit from work, are largely influenced by social norms (Liefbroer and Billari, 2010; Settersten and Hagestad, 1996). Moreover, norms may exist regarding the combination of certain statuses, such as worker and retiree. Even though in policy debates the combination of work and retirement may be promoted in order to deal with an ageing population, in public discourse extending working life past the statutory retirement age may not be necessarily supported. It may also be evaluated as anti-social behaviour in the sense that it could hinder opportunities for career mobility among the younger generation (Van Dalen and Henkens, 2002). We would argue that bridge employment is more likely in contexts where there is normative support for paid work after retirement than in countries with limited support for this norm (Hypothesis 8).

\section{Data and methods}

\section{Data}

Data for this study came from the fourth wave of the Survey of Health, Ageing and Retirement in Europe (SHARE) project. The data collection was carried out in 2011 and provided information on 16 countries (see the online Appendix, Table A1; Börsch-Supan et al., 2013). The analytical sample for the current study was restricted to the birth cohorts of 1936 to 1951. At the time of measurement, these respondents were aged between 60 and 75. In most countries, retirement pensions can be received as early as 60 and bridge employment often starts relatively shortly after career exit (Maestas, 2010), so this age range seemed the most appropriate. In this study, retirement is understood as the receipt of a pension income. Respondents were asked to indicate whether they received a form of public and/or occupational pension income. Those who did not receive any form of pension income (i.e. those still in their main careers) were excluded from the analyses. Individuals who received retirement income but had not worked before (e.g. traditional homemakers) were also excluded so as to overcome the problem that these persons are not likely to seek bridge jobs. There were missing values for some of the relevant variables, so 2.5 per cent of the remaining cases were excluded. The final sample size was 22,485 . The mean age in the analytical sample was 68 , and women made up 54 per cent of the respondents. 


\section{Dependent variable: bridge employment}

Following previous empirical research (Parry and Bown Wilson, 2014), bridge employment is defined as participation in paid work while receiving a pension income. Retirees without paid work were placed in the 'full retirement' group (0). Those retirees who answered the questions regarding their current job were coded as 'bridge employees' (1).

\section{Independent variables: individual-level characteristics}

To measure educational attainment, the International Standard Classification of Education (ISCED) classification was used (UNESCO, 2006). The classification is based on information from country-specific questions on the highest qualification that respondents have obtained. The seven-category ISCED variable was grouped into three basic levels. Primary educational levels were categorized as 'low' (1); secondary educational levels were categorized as 'middle' (2); and tertiary educational levels were categorized as 'high' (3). In addition, respondents were asked to report the amount of income they received from several pension arrangements. We used a pension income measure constructed by the SHARE-team that combines the income from old age pension and early pension arrangements. To deal with the skewed distribution of pension income, natural $\log$ of the pension income was included in the estimation. General health status was measured in SHARE by asking: 'Would you say your health is ...'. The answer categories were: 'excellent' (1), 'very good' (2), 'good' (3), 'fair' (4), or 'poor' (5). The answer categories were rescaled such that a high score indicated excellent health.

For current marital status, a four-category variable was constructed: (1) married (including marriage with or without living together and registered partnership); (2) never married; (3) divorced; and (4) widowed. The informal care tasks that respondents undertook were measured by asking whether they provided help to others outside the household. If the question was answered positively, respondents were asked: 'In the last 12 months, how often altogether have you given personal care or practical household help to this person?'. The answer categories were 'every day', 'every week', 'every month', or 'less often'. A dummy variable was constructed to indicate whether a respondent had daily care tasks (1) or not (0) because this would most likely limit the time they could devote to paid work.

Another indicator for regular care tasks was whether people had grandchildren to look after on a daily basis. First, respondents were asked: 'How many children do you have who are still alive?'. Then respondents were asked: 'Talking about grandchildren, how many grandchildren do you have?'. We constructed a variable to indicate whether respondents had 'no children or grandchildren' (0), 'children, but no grandchildren' (1), or 'grandchildren' (2). Respondents with grandchildren were then asked: 'During the last 12 months, have you regularly or occasionally looked after your grandchild(ren)?'. The answer categories were 'almost daily', 'almost every week', 'almost every month', or 'less often'. Similar to the operationalization of informal caregiving, respondents who looked after their grandchildren almost every day were placed into the category 'grandchildren, daily care tasks' (3).

The descriptive statistics of the independent variables are presented in Table 1. 
Table I. Descriptive statistics of the individual-level indicators.

\begin{tabular}{lcc}
\hline & Mean & SE \\
\hline Female & 0.53 & 0.50 \\
Age & & \\
$\quad 60-63$ & 0.22 & 0.42 \\
$64-67$ & 0.28 & 0.45 \\
$68-71$ & 0.27 & 0.44 \\
$72-75$ & 0.23 & 0.42 \\
Educational attainment & & \\
Low & 0.20 & 0.40 \\
Middle & 0.60 & 0.49 \\
High & 0.20 & 0.40 \\
Pension income (per I000 euros) & 10.80 & 14.13 \\
Health (range: I-5) & 2.70 & 1.05 \\
Marital status & & \\
Married & 0.73 & 0.44 \\
Never married & 0.05 & 0.21 \\
Divorced & 0.09 & 0.28 \\
Widowed & 0.13 & 0.33 \\
Daily informal care tasks & 0.07 & 0.24 \\
(Grand)Children & & \\
No children & 0.08 & 0.28 \\
Children, no grandchildren & 0.14 & 0.35 \\
Grandchildren, no daily care & 0.69 & 0.46 \\
Grandchildren, daily care & 0.09 & 0.28 \\
\hline
\end{tabular}

Source: SHARE, wave 4, 20 I I.

\section{Independent variables: societal characteristics}

Information on the generosity of the pension context was obtained from Eurostat (data for 2011; see http://ec.europa.eu/eurostat/). The measure expenditure on pensions represents the public spending on pensions as a percentage of a country's GDP. We adjusted this measure to account for the age structure in each country. We divided expenditure on pensions by the old-age dependency ratio, which we retrieved from the World Bank (data for 2011; see http://data.worldbank.org). This ratio represents the proportion of people older than 64 to the working population (aged 15 to 64). The higher the score for this newly computed variable, the more generous the pension climate for older citizens. In the analyses, we multiplied the scores by 10 to increase interpretability.

To determine the normative support for bridge employment, a measure from the special edition of the Eurobarometer was used (TNS Opinion \& Social, 2012) in which it was asked to what extent people believed that 'older adults should be able to continue working past the official retirement age'. The answer categories were: 'they should be able to continue', 'they should have to stop working' or 'don't know'. We used the percentage that answered that older adults 'should be able to continue' to measure support 
for working past retirement. In the analyses, we also multiplied this variable by 10 , which means that the estimated coefficient corresponds to an increase of 10 per cent in normative support for working past retirement. Unfortunately, data for Switzerland were not available, which limited the analyses on this issue to 15 countries.

\section{Analytical strategy}

To deal with the dependency of observations in our hierarchically structured dataset, a multilevel modelling approach was required (Bryan and Jenkins, 2013). Specifically, multilevel logit models were estimated in order to account for the binary nature of our dependent variable (Guo and Zhao, 2000). A sufficiently large sample size at the country level is needed to limit estimation bias in multilevel models. Even though there is a lack of consensus about the required size of the sample (Bryan and Jenkins, 2013), it is clear that our sample of 16 countries is relatively small from a multilevel modelling perspective. Nevertheless, it still enabled us to investigate the effect of a limited number of country-level characteristics on bridge employment (Engelhardt, 2012; Hank and Erlinghagen, 2011; Komp et al., 2010). The robustness of the results was checked using clustered bootstrapping methodology. Even though it is by no means perfect, it is a way to investigate whether sampling differences affect the robustness of the results. The sensitivity analyses did not show substantial deviations from the standard multilevel logit models presented below.

\section{Results}

\section{Descriptive results}

On average, 11 per cent of older adults between the ages of 60 and 75 participated in bridge employment with considerable variation across the investigated countries. For example, while working after retirement was quite exceptional in countries such as Spain $(3 \%)$, Slovenia (3\%), Poland (5\%) and France (5\%), it was relatively common among retirees in Estonia (22\%), Sweden (21\%), Switzerland (20\%) and Denmark (14\%). Figure 1 shows that the degree of gender inequality in participation in bridge employment also varies by country. Even though the overall conclusion was that men were more likely to participate in bridge jobs compared to women, gender differences seemed to be very small in countries such as Austria, Spain and Estonia. Relatively large differences were found in Denmark, the Netherlands and Sweden.

With regard to the characteristics of the pension context (i.e. expenditure on pensions and support for the norm that older adults should be able to work after retirement), Figure 2 shows considerable variation across countries. For instance, expenditure on pensions was relatively high in Austria and Poland, while relatively low levels of expenditure were found in Estonia and Sweden. At the same time, Denmark and the Netherlands were found to have relatively high levels of normative support for combining work and retirement, while the support was rather low in Slovenia and Italy. Overall, what is concluded from this figure is that the association between expenditure on pensions and normative support for working after retirement is rather weak. 


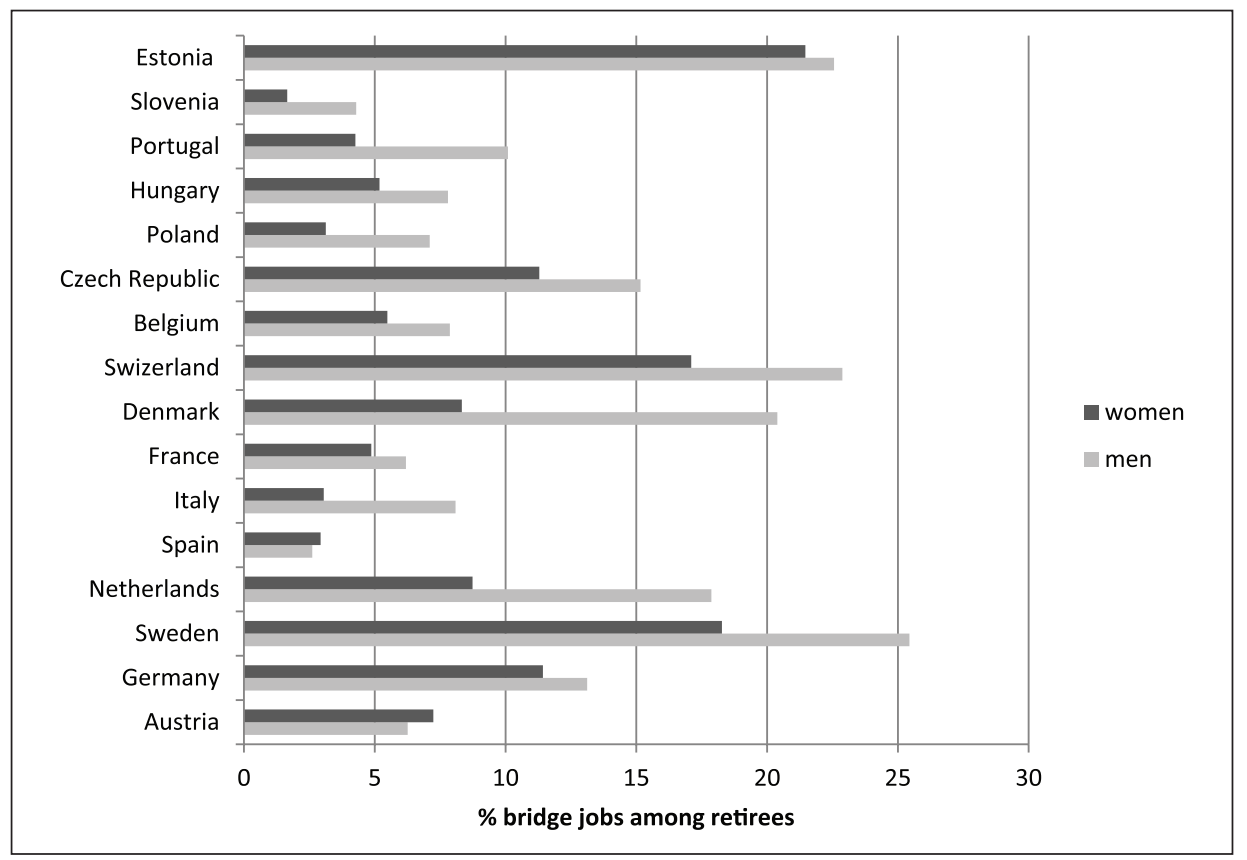

Figure I. Bridge employment across 16 European countries by gender. Source: SHARE, wave 4, $201 \mathrm{I}$.

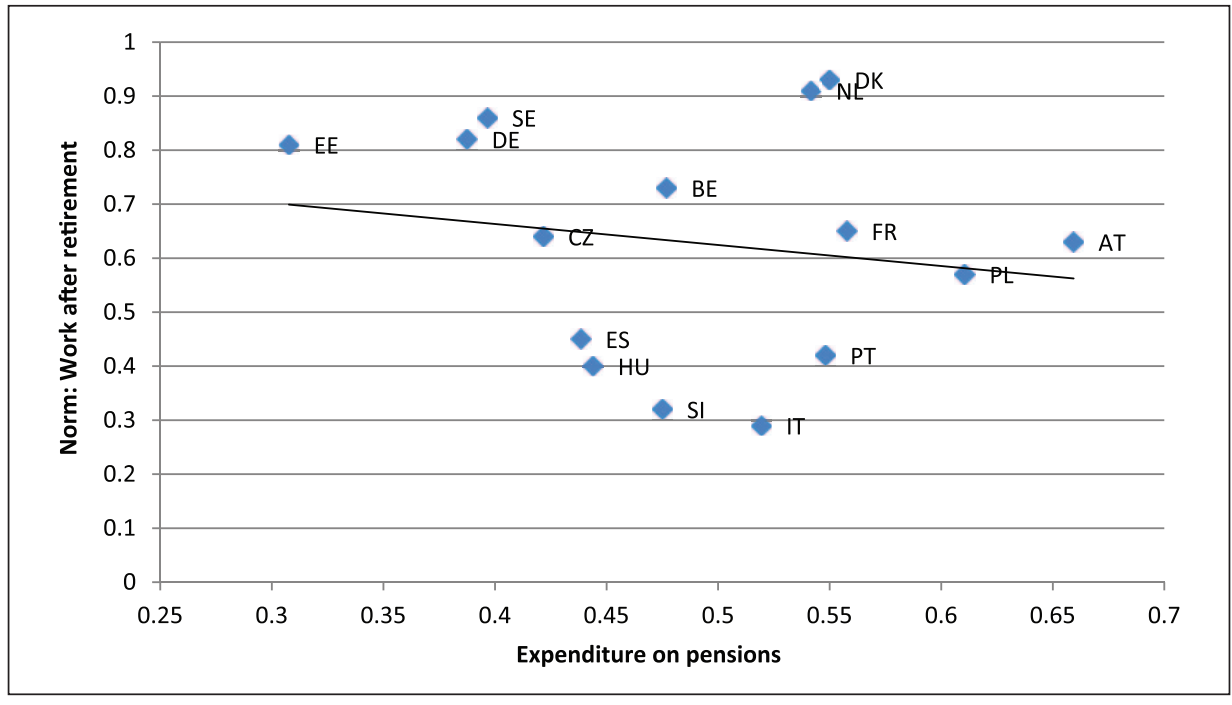

Figure 2. Expenditure on pensions and normative support for working after retirement for 16 European countries.

Source: SHARE, wave 4, 201 I.

Note: for country IDs, check the online Appendix, Table AI. 


\section{Multivariate analyses: who participates in bridge employment?}

Table 2 presents the estimates from the multilevel logit models explaining participation in bridge employment versus full retirement based on individual- and societal-level factors. Model 1 presents the coefficients for the individual-level variables. First, high instead of low educational attainment $(\mathrm{OR}=2.64)$ was shown to be related to a higher likelihood of working in bridge jobs rather than fully retiring, which supports Hypothesis 1. Higher pension income was found to relate to a lower likelihood to work past retirement $(\mathrm{OR}=0.94)$, supporting Hypothesis 2. Support was also found for Hypothesis 3, namely that better health was related to a higher likelihood of participating in bridge jobs compared to retiring fully $(\mathrm{OR}=1.54)$. In addition, the results in model 1 showed that bridge employment was less likely with increasing age.

Also, marital status appeared to be a significant predictor. In particular, retirees who had experienced divorce or widowhood were more likely to work in bridge jobs compared to married retirees (Hypothesis 4). The results in model 1 also showed that retirees who had children but no grandchildren and those who daily cared for grandchildren were more likely to work in bridge jobs as compared to their childless counterparts. However, grandparents who had daily care responsibilities were not more or less likely to work in bridge jobs as compared to grandparents without daily care for their grandchildren. Hypothesis 5 could thus not be supported.

In additional analyses, the interactions between gender and the family domain characteristics were tested (online Appendix, Table A2). The results showed that the relationship between marital status and bridge employment was different for men and women. Specifically, women who experienced a divorce $(\mathrm{OR}=1.48)$ or widowhood $(\mathrm{OR}=2.48)$ were more likely to work in bridge jobs as compared to their male counterparts (Hypothesis 6). Being never married did not have a differential impact on the likelihood of bridge employment participation among men and women. Also, no gender differences were found in the relationships between informal caregiving tasks and bridge employment. Moreover, the differential impact of the social standing variables for men and women was tested (data available upon request). The results showed that age and pension income interact with gender. First, while age negatively relates to the likelihood of working in bridge jobs among men, this effect was found to be stronger for women. Second, pension income was also shown to have a stronger negative impact for women as compared to men.

Next, the country-level variables were included into the explanatory model for bridge employment in models 2 to 4 in Table 2. Overall, the explained variance increased from 15 per cent in model 1 to about 20 per cent after including the country-level variables into the estimation. In model 2 , we included expenditure on pensions in the analysis. In model 3, the measure for normative support for working after retirement was tested. Finally, in model 4, both these societal factors were estimated simultaneously. Model 4 provides support for our hypothesis (Hypothesis 7) that bridge employment is more likely in countries where the expenditure on pensions is lower than in countries with relatively high pension expenditure $(\mathrm{OR}=0.70)$. In addition, in line with Hypothesis 8 , it was found that stronger support for the norm that older adults should be able to work past official retirement age was associated with a higher likelihood of working in bridge jobs $(\mathrm{OR}=1.19){ }^{1}$ 
Table 2. Multilevel logit model to predict bridge employment: individual-level and societal-level factors.

\begin{tabular}{|c|c|c|c|c|c|c|c|c|}
\hline & \multicolumn{2}{|l|}{ Model I } & \multicolumn{2}{|l|}{ Model 2} & \multicolumn{2}{|c|}{ Model 3a } & \multicolumn{2}{|l|}{ Model 4a } \\
\hline & Logit & SE & Logit & SE & Logit & SE & Logit & SE \\
\hline \multicolumn{9}{|l|}{ Individual level } \\
\hline Female & $-0.40 * *$ & 0.05 & $-0.40 * *$ & 0.05 & $-0.4 \mid * *$ & 0.05 & $-0.4 I * *$ & 0.05 \\
\hline \multicolumn{9}{|l|}{ Age } \\
\hline \multicolumn{9}{|l|}{ 60-63 (ref) } \\
\hline $64-67$ & $-0.43 * *$ & 0.06 & $-0.42 * *$ & 0.06 & $-0.46 * *$ & 0.06 & $-0.46 * *$ & 0.06 \\
\hline $68-71$ & $-0.67 * *$ & 0.07 & $-0.67 * *$ & 0.07 & $-0.68 * *$ & 0.07 & $-0.68 * *$ & 0.07 \\
\hline $72-75$ & $-1.32 * *$ & 0.08 & $-1.33 * *$ & 0.08 & -1.32 ** & 0.08 & $-1.32 * *$ & 0.08 \\
\hline \multicolumn{9}{|l|}{ Educational attainment } \\
\hline \multicolumn{9}{|l|}{ Low (ref) } \\
\hline Middle & $0.28 * *$ & 0.08 & $0.28 * *$ & 0.08 & $0.35 * *$ & 0.09 & 0.35 ** & 0.09 \\
\hline High & $0.97 * *$ & 0.09 & $0.97 * *$ & 0.09 & $1.05 * *$ & 0.09 & $1.04 * *$ & 0.09 \\
\hline Pension income (In) & $-0.05 * *$ & 0.01 & $-0.05 * *$ & 0.01 & $-0.06 * *$ & 0.01 & $-0.06 * *$ & 0.01 \\
\hline Health status & $0.43 * *$ & 0.02 & $0.43 * *$ & 0.02 & $0.45 * *$ & 0.03 & $0.45 * *$ & 0.03 \\
\hline \multicolumn{9}{|l|}{ Marital status } \\
\hline \multicolumn{9}{|l|}{ Married (ref) } \\
\hline Never married & 0.16 & 0.12 & 0.16 & 0.12 & 0.14 & 0.13 & 0.14 & 0.13 \\
\hline Divorced & $0.41 * *$ & 0.07 & $0.4 I * *$ & 0.07 & $0.40 * *$ & 0.08 & $0.40 * *$ & 0.08 \\
\hline Widowed & $0.25 * *$ & 0.08 & $0.25 * *$ & 0.08 & $0.26 * *$ & 0.08 & $0.26 * *$ & 0.08 \\
\hline Daily informal care tasks & -0.10 & 0.10 & -0.10 & 0.10 & -0.11 & 0.10 & -0.11 & 0.10 \\
\hline \multicolumn{9}{|l|}{ (Grand)Children } \\
\hline \multicolumn{9}{|l|}{ No children (ref) } \\
\hline $\begin{array}{l}\text { Children, no } \\
\text { grandchildren }\end{array}$ & $0.29 * *$ & 0.11 & $0.29 * *$ & 0.11 & $0.33 * *$ & 0.12 & $0.32 * *$ & 0.12 \\
\hline $\begin{array}{l}\text { Grandchildren, no } \\
\text { daily care }\end{array}$ & 0.18 & 0.10 & 0.18 & 0.10 & $0.24 *$ & 0.11 & $0.24 *$ & 0.11 \\
\hline $\begin{array}{l}\text { Grandchildren, daily } \\
\text { care }\end{array}$ & $0.24 *$ & 0.11 & $0.24 *$ & 0.11 & $0.30 * *$ & 0.11 & $0.29 *$ & 0.11 \\
\hline \multicolumn{9}{|l|}{ Societal level } \\
\hline Expenditure on pensions & & & $-0.42 *$ & 0.18 & & & $-0.36 * *$ & 0.13 \\
\hline $\begin{array}{l}\text { Norm: work past } \\
\text { retirement }\end{array}$ & & & & & $0.21 * *$ & 0.07 & $0.18 * *$ & 0.06 \\
\hline Var (intercept) & $0.5 \mathrm{I} * *$ & 0.19 & 0.37 *** & 0.14 & $0.29 * *$ & 0.11 & $0.18 * *$ & 0.07 \\
\hline Total explained variance & 0.153 & & 0.176 & & 0.206 & & 0.225 & \\
\hline
\end{tabular}

Source: SHARE, wave 4, 20I I. Level I: $N=22,485$; Level 2: $N=16$.

$* p \leqslant 0.05 ; * * p \leqslant 0.01$.

aSwitzerland excluded. Level I: $N=21,255$; Level 2: $N=15$.

SE, standard error.

In addition to presenting the results of the multivariate analyses on the relationship between societal factors and bridge employment in Table 2, these relationships are also graphically illustrated. Figures 3 and 4 depict the scores for the societal variables as 


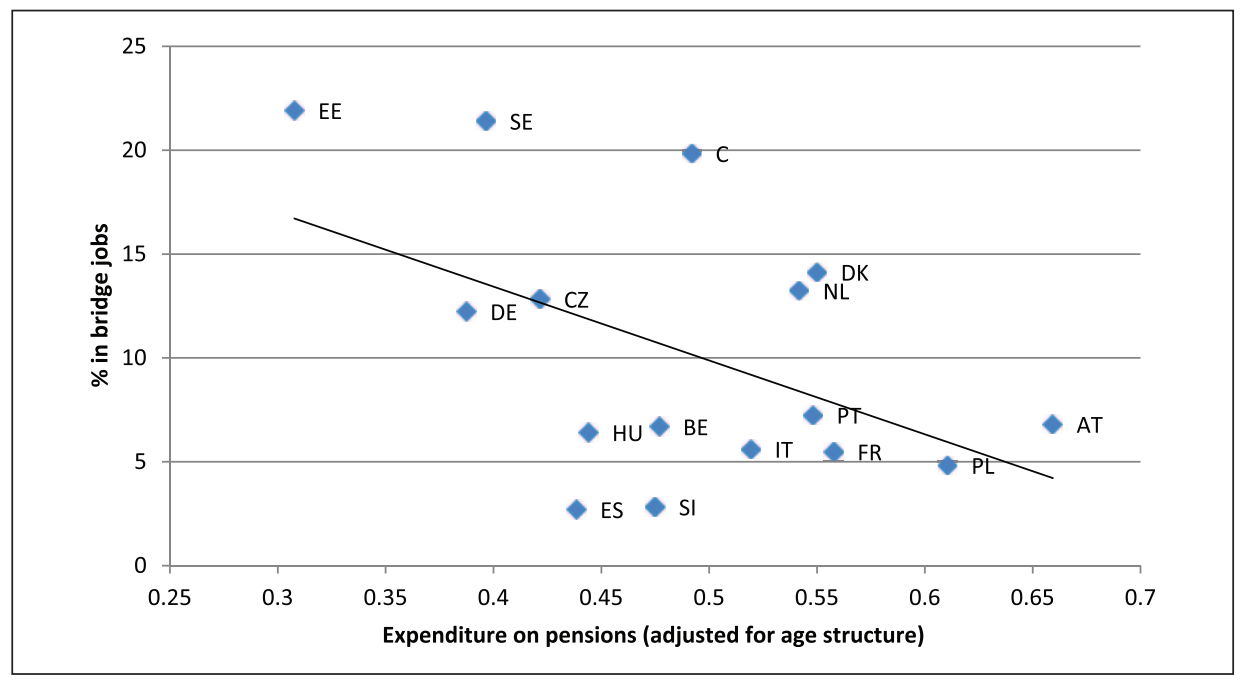

Figure 3. Expenditure on pensions and participation in bridge jobs by country. Source: SHARE, wave 4, $201 \mathrm{I}$. Note: for country IDs, check the online Appendix, Table AI.

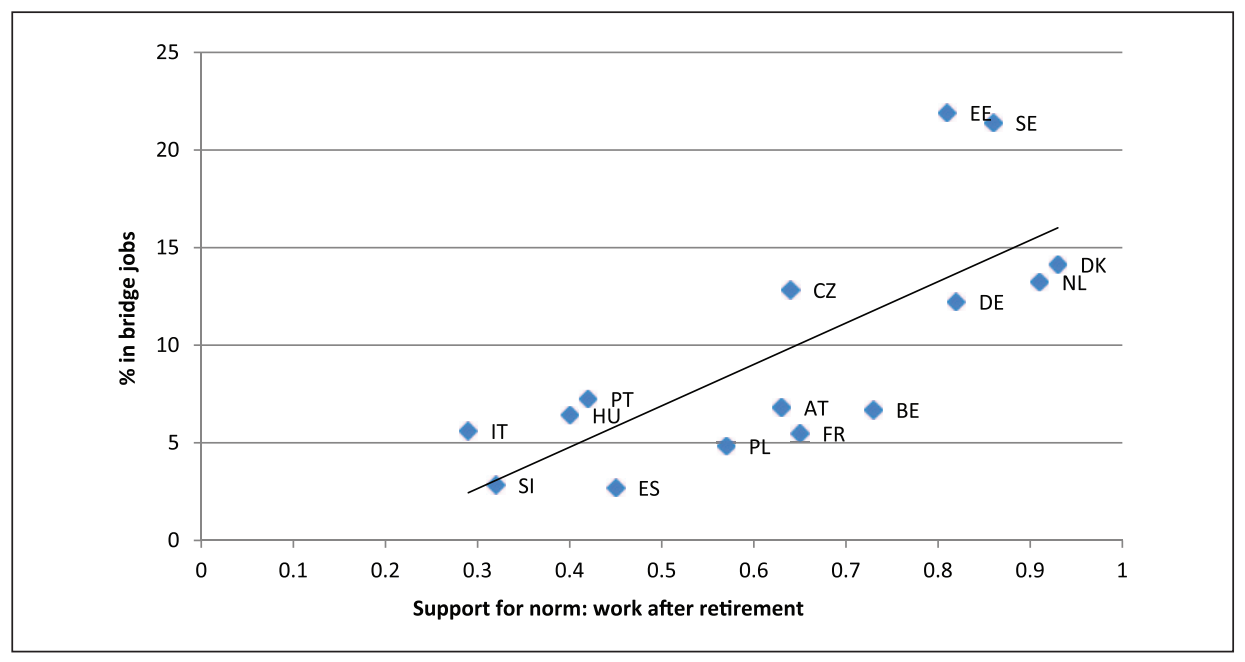

Figure 4. Support for the norm to work after retirement and participation in bridge jobs by country.

Source: SHARE, wave 4, 201 I.

Note: for country IDs, check the online Appendix, Table AI.

related to the share of retirees participating in bridge jobs. While a negative association between bridge employment and expenditure on pensions is shown in Figure 3, a positive relationship between bridge employment and normative support for working after retirement is shown in Figure 4. Overall, Figures 3 and 4 illustrate that economic and 
social aspects of the pension context may have different effects on the likelihood of participation in bridge employment.

\section{Explorative analyses: how to explain the number of hours that bridge employees work?}

A further relevant question in relation to bridge employment participation is to what extent people are involved in these bridge jobs (i.e. how many hours they work). Therefore, we further explored to what extent our explanatory model of bridge employment participation (Table 2) also explained variation in the number of hours that bridge employees worked per week. On the individual level, the results (online Appendix, Table A3) suggested that women worked on average 4 to 5 hours less than men. Moreover, pension income was negatively related to the number of work hours. On the country level, it was found that, after controlling for composition effects, higher expenditures on public pensions were related to a lower number of working hours. Normative support for working after public pension age was negatively related to the number of working hours, which contrasted to the positive relationship between support and actual participation in bridge employment (Table 2).

Figure 5 is presented to better understand this interesting finding. The bivariate relationship illustrates that in countries such as Italy, Spain and Hungary, relatively low levels of support for working past retirement were associated with relatively high numbers of working hours. In these countries, work in old age might not be viewed as desirable due to relatively high levels of (youth) unemployment or the forced nature of bridge employment due to financial necessity. Bridge employment was relatively uncommon here, but those who were working, did so in a substantial way. In countries such as Denmark, Sweden and the Netherlands, high support for working after retirement might make bridge employment common but only as one of the activities among others. In these countries a substantial lower number of hours is worked in bridge jobs.

\section{Discussion}

In the current study, the determinants of bridge employment in Europe were investigated by using data for 16 European countries. The results of the study reveal that the number of retirees working in paid employment while receiving pensions differs widely across Europe, with Estonia, Sweden and Switzerland having the highest levels of participation. The difference between men and women also varies to a large extent across countries. Even though the general conclusion is that men are more likely to participate in bridge jobs after career exit, in countries such as Austria, Spain and Estonia the differences between men and women are rather small.

To find an explanation for these differences in bridge employment across Europe, three sets of factors were incorporated into our model, namely factors related to individuals' standing in social hierarchy, family-related factors and broader societal characteristics. These factors proved to be highly relevant in explaining bridge employment, which aligns with sociological assumptions on the embeddedness of individual behaviour in the social context. At the country level, the results of our investigation show that when more 


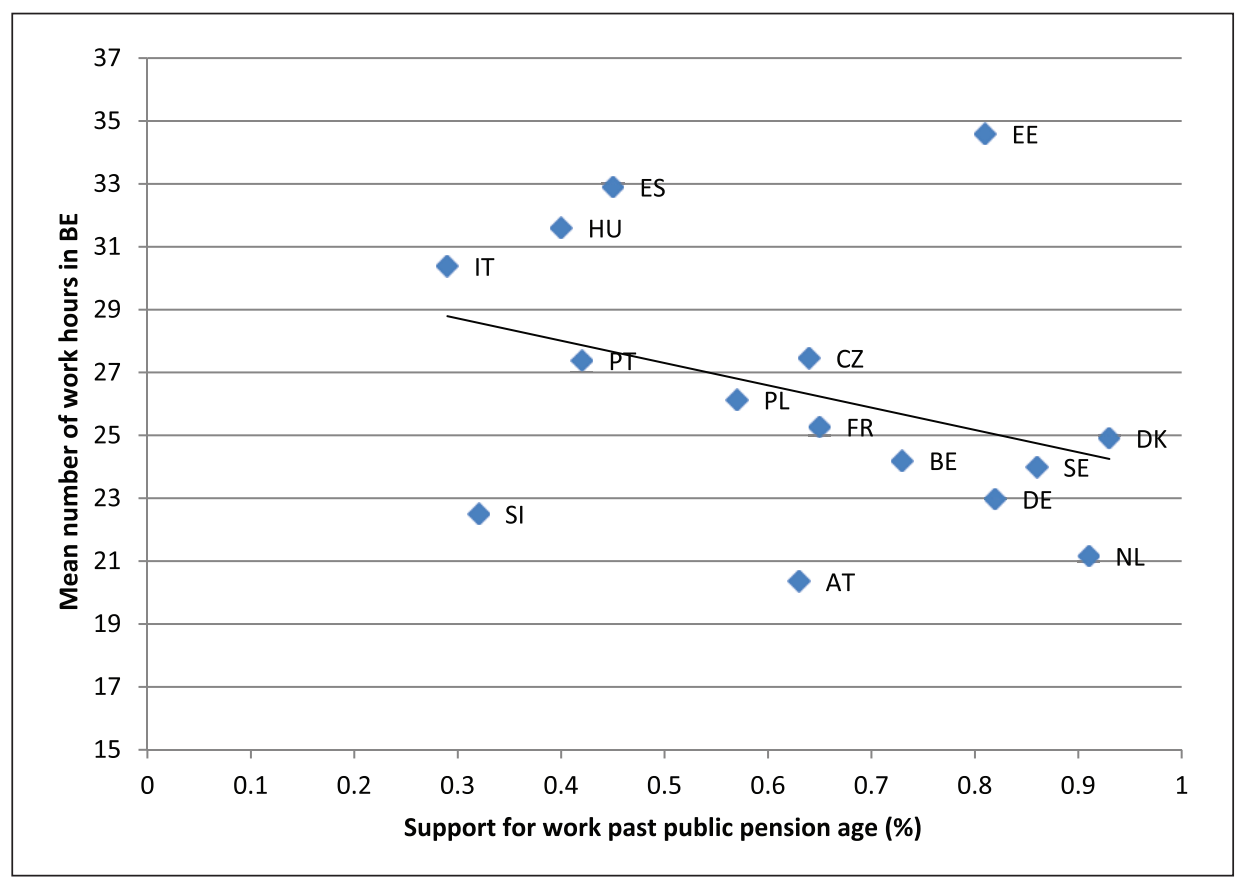

Figure 5. Support for the norm to work after retirement and the average number of hours that bridge employees worked per week.

Source: SHARE, wave 4, $201 \mathrm{I}$.

Note: for country IDs, check the online Appendix, Table AI.

public pension resources are available, older adults tend not to undertake paid employment after retirement. At the same time, we also found that a supportive environment regarding prolonging work careers after retirement is positively associated with participation in bridge employment. Apparently, not only economic incentives, but also normative signs regarding the prolongation of work careers after retirement influence the decision-making process regarding bridge employment.

At the individual level, bridge employment is found to be particularly likely among highly educated and healthy retirees. As such, this seems to provide additional support for the idea that these groups of retirees are most likely to be intrinsically motivated and committed to work (Jones and McIntosh, 2010; Wang et al., 2008), while at the same time having more opportunities to continue working after retirement compared to their lower-educated and less healthy counterparts (Dingemans et al., 2015; Komp et al., 2010). When we control for these aspects, our results also show that higher individual pension income associates with a lower likelihood of bridge employment, especially in the case of women. The fact that low pension income is a particularly strong driving force for women to work past retirement suggests that women, more than men, work past retirement to fulfil financial needs. Gender differences were also found for marital status: being divorced or widowed was related to a higher likelihood to work in bridge jobs for 
women as compared to their male counterparts. Financial reasons may explain these findings, particularly in the case of divorced women, who have been argued to be economically vulnerable in retirement. In addition, the importance that women - more than men - attach to the relational attributes of work may be another explanation (Konrad et al., 2000).

The results illustrate that the decision to participate in bridge employment is not taken in isolation, but is influenced by the social environment. We further explored to what extent our explanatory model for participation in bridge employment also explains how many hours retirees work past retirement. Although research on the number of work hours in relation to bridge employment may increase our understanding of how important bridge jobs are in the lives of retirees, this topic has received very limited attention to date. The results show a lower number of work hours for women than for men. Moreover, more individual pension income is related to a lower number of work hours. The most surprising finding is that higher normative support for working after the public pension age relates to a lower number of work hours. Taking the findings of this study together, it could be suggested that when support for work after retirement is low and bridge employment is relatively uncommon, those who work in bridge jobs do so for many hours. It is likely that they have financial needs that force them to work for a substantial number of hours (Dingemans and Henkens, 2014). By contrast, countries with a supporting culture towards working after retirement seem to have relatively high numbers of bridge employees, but on average they work fewer hours. In these countries, working after retirement could be understood as a way to gradually transition from fulltime work to full-time retirement - a notion that is central to the concept of bridge employment in most psychological studies. Even though this study explores working hours in post-retirement jobs, further studies need to be conducted on this issue to better understand the determining forces on the number of hours that bridge employees work.

The current investigation has several strengths as well as limitations that need to be taken into account when interpreting the results. A clear advantage of our approach is that we can compare the extent to which European retirees combine income from paid work with pension benefits, and as such we are among only a handful of researchers to provide insights on cross-national variation in participation in bridge jobs. In addition, the investigation of the explanatory model of bridge employment in terms of crossnational data has enabled us to unravel societal factors that relate to the participation in bridge employment and the number of hours that retirees work in these bridge jobs. However, we need to recognize that, even though the SHARE data provide a rich source of information on work and retirement patterns in Europe, it also has some drawbacks. One clear limitation is the cross-sectional nature of our research. Despite the panel character of SHARE, the limited number of retirement transitions in the data hampers a longitudinal investigation of our research questions. Consequently, the cross-sectional design limits any causal interpretation of the findings, such as determining the effect of normative aspects on behaviour. Changes in retirement behaviour can be the result of changing normative views on retirement, but it may also be the other way around, with the increasing trend towards bridge employment itself establishing a norm for the combination of work and retirement. This reciprocity is part of Giddens' theory of 
structuration from which it follows that societal factors influence individual behaviour as well as that individual behaviour reproduces societal institutions (Giddens, 1984). More research on this relationship is needed in order to gain a better understanding of the reciprocity between norms and behaviour.

Another limitation is that only a limited number of country-level factors could be investigated simultaneously because only 16 countries were included in our dataset. Although the estimated models provide robust results for our two societal characteristics in relation to bridge employment, it was not possible to include additional information based on other institutional domains in the pension context. Further scientific investigation of other potential societal determinants, such as labour market characteristics and juridical aspects of pension systems, would also be of benefit to policymakers. Finally, it must be noted that the results of the study cannot be generalized to Europe because only a non-random selection of European countries was investigated.

To conclude, our study shows that the decision on bridge employment needs to be evaluated in its social environment. It is not driven solely by individual-level determinants, but also strongly depends on influences from the broader social environment, such as the economic and normative characteristics of modern societies. With the prospect of the potential unsustainability of pension systems because of their reliance on transfers from the younger to the older generation in pay-as-you-go public pension systems (Bongaarts, 2004), policymakers and politicians would benefit greatly from increased insights on the societal characteristics of post-retirement life and their association with the decision or need to extend working life. Further research in this field could help them to identify and implement policy reforms in order to deal with the changing demographic landscape and those changes particular to the composition of their respective workforces.

\section{Acknowledgements}

Kène Henkens and Hanna van Solinge were affiliated to the Netherlands Institute for Advanced Study in the Humanities and Social Sciences (NIAS) during the revision of this article.

This article uses data from SHARE, wave 4, release 1.1.1, as of 28 March 2013. The SHARE data collection has been primarily funded by the European Commission through the 5th Framework Programme (project QLK6-CT-2001-00360 in the thematic programme Quality of Life), through the 6th Framework Programme (projects SHARE-I3, RII-CT-2006-062193, COMPARE, CIT5-CT-2005-028857 and SHARELIFE, CIT4-CT-2006-028812), and through the 7th Framework Programme (SHARE-PREP, N ${ }^{\circ}$ 211909, SHARE-LEAP, N ${ }^{\circ} 227822$ and SHARE M4, $\mathrm{N}^{\circ}$ 261982). Additional funding from the U.S. National Institute on Aging (U01 AG09740-13S2, P01 AG005842, P01 AG08291, P30 AG12815, R21 AG025169, Y1-AG-455301, IAG BSR06-11 and OGHA 04-064) and the German Ministry of Education and Research, as well as from various national sources, is gratefully acknowledged (see www.share-project.org for a full list of funding institutions).

\section{Funding}

This work was supported by MaGW Research Talent Grant (406-11-029) awarded to Kène Henkens and Ellen Dingemans by the Netherlands Organization for Scientific Research (NWO). 


\section{Note}

1. We followed the suggestion of anonymous reviewers to test additional country-level characteristics, such as GDP per capita, state pension age and welfare state typology. All these factors were not found to significantly impact the likelihood to participate in bridge employment.

\section{References}

Adams GA and Rau B (2004) Job seeking among retirees seeking bridge employment. Personnel Psychology 57: 719-44.

Beehr TA and Bennett MM (2015) Working after retirement: features of bridge employment and research directions. Work, Aging and Retirement 1: 112-28.

Bongaarts J (2004) Population aging and the rising cost of public pensions. Population and Development Review 30: 1-23.

Börsch-Supan A, Brandt M, Hunkler C, Kneip T, Korbmacher J, Malter F, Schaan B, Stuck S and Zuber S; SHARE Central Coordination Team (2013) Data resource profile: the Survey of Health, Ageing and Retirement in Europe (SHARE). International Journal of Epidemiology 42: 992-1001.

Bowman JR (2014) Capitalisms Compared: Welfare, Work and Business. Thousand Oaks, CA: SAGE/CQ Press.

Brunello G and Langella M (2012) Bridge jobs in Europe. IZA Discussion Papers Series, October. Bonn: The Institute for the Study of Labor (IZA), 1-39.

Bryan ML and Jenkins SP (2013) Regression Analysis of Country Effects Using Multilevel Data: A Cautionary Tale. Colchester: Institute for Social and Economic Research.

Cahill KE, Giandrea MD and Quinn JF (2006) Retirement patterns from career employment. The Gerontologist 46: 514-23.

Carr DC and Kail BL (2012) The influence of unpaid work on the transition out of full-time paid work. The Gerontologist 53: 92-101.

Damman M (2014) From Employee to Retiree: Life Histories and Retirement in the Netherlands. Amsterdam: Amsterdam University Press, 170.

Damman M, Henkens K and Kalmijn M (2015) Missing work after retirement: the role of life histories in the retirement adjustment process. The Gerontologist 55: 802-13.

Dingemans E and Henkens K (2014) Involuntary retirement, bridge employment, and satisfaction with life: a longitudinal investigation. Journal of Organizational Behavior 35: 575-91.

Dingemans E, Henkens K and Van Solinge H (2015) Access to bridge employment: who finds and who does not find work after retirement? The Gerontologist. Epub ahead of print 11 February. DOI: $10.1093 /$ geront/gnu182.

Eagly AH, Wood W and Diekman AB (2000) Social role theory of sex differences and similarities: a current appraisal. In: Eckes T and Trautner HM (eds) The Developmental Social Psychology of Gender. Mahwah, NJ: Lawrence Erlbaum Associates, 123-74.

Engelhardt H (2012) Late careers in Europe: effects of individual and institutional factors. European Sociological Review 28: 550-64.

Eurofound (2011) Part-Time Work in Europe. European Company Survey 2009. Dublin: Eurofound.

Feldman DC (1994) The decision to retire early: a review and conceptualization. Academy of Management Review 19: 285-311.

Feldman DC and Beehr TA (2011) A three-phase model of retirement decision making. American Psychologist 66: 193-203.

Giddens A (1984) The Constitution of Society: Outline of the Theory of Structuration. Berkeley, CA; Los Angeles, CA: University of California Press. 
Gobeski KT and Beehr TA (2009) How retirees work: predictors of different types of bridge employment. Journal of Organizational Behavior 30: 401-25.

Guo G and Zhao H (2000) Multilevel modeling for binary data. Annual Review of Sociology 26: 441-62.

Hank K and Erlinghagen M (2011) Perceptions of job security in Europe's ageing workforce. Social Indicator Research 103: 427-42.

Heckman JJ (1979) Sample selection bias as a specification error. Econometrica 47: 153-61.

Hochfellner D (2013) Labor Market Participation of Older Workers: Employment beyond Retirement and Old Age Poverty. Bamberg: Fakultät Sozial- und Wirtschaftswissenschaften, Universität Bamberg.

Jones DA and McIntosh BR (2010) Organizational and occupational commitment in relation to bridge employment and retirement intentions. Journal of Vocational Behavior 77: 290-303.

Kalmijn M and Kraaykamp G (2007) Social stratification and attitudes: a comparative analysis of the effects of class and education in Europe. The British Journal of Sociology 58: 547-76.

Kantarci T (2012) Essays on Partial Retirement. Tilburg: Center Dissertation Series.

Kim H and De Vaney SA (2005) The selection of partial or full retirement by older workers. Journal of Family and Economic Issues 26: 371-94.

Kim S and Feldman DC (2000) Working in retirement: the antecedents of bridge employment and its consequences for quality of life in retirement. Academy of Management Journal 43: $1195-210$.

Komp K, Van Tilburg T and Broese van Groenou M (2010) Paid work between age 60 and 70 years in Europe: a matter of socio-economic status? International Journal of Ageing and Later Life 5: 45-75.

Konrad AM, Ritchie JE, Lieb P and Corrigall E (2000) Sex differences and similarities in job attribute preferences: a meta-analysis. Psychological Bulletin 126: 593-641.

Larsen M and Pedersen PJ (2013) To work, to retire - or both? Labor market activity after 60. IZA Journal of European Labor Studies 2: 21-41.

Liefbroer AC and Billari FC (2010) Bringing norms back in: a theoretical and empirical discussion of their importance for understanding demographic behaviour. Population, Space and Place 16: $287-305$.

Lindbeck A, Nyber S and Weibull JW (1999) Social norms and economic incentives in the welfare state. The Quarterly Journal of Economics 114: 1-35.

Maestas N (2010) Back to work. Expectations and realizations of work after retirement. The Journal of Human Resources 45: 718-48.

Maestas N and Zissimopoulos JM (2010) How longer work lives ease the crunch of population aging. Journal of Economic Perspectives 24: 139-60.

Oude Mulders J, Van Dalen HP, Henkens K and Schippers J (2014) How likely are employers to rehire older workers after mandatory retirement? A vignette study among managers. De Economist 162: 415-31.

Parry E and Bown Wilson D (2014) Career transitions at retirement in the United Kingdom: bridge employment or continued progression? In: Alcover C-M, Topa G, Parry E, Fraccarioli F and Depolo M (eds) Bridge Employment: A Research Handbook. New York: Routledge, 138-53.

Pienta AM and Hayward MD (2002) Who expects to continue working after age 62? The retirement plans of couples. Journal of Gerontology Series B: Psychological Sciences and Social Sciences 57: 199-208.

Pleau RL (2010) Gender differences in postretirement employment. Research on Aging 32: 267-303.

Radl J (2013) Labour market exit and social stratification in Western Europe: the effects of social class and gender on the timing of retirement. European Sociological Review 29: 654-68. 
Raymo JM and Sweeney MM (2006) Work-family conflict and retirement preferences. Journal of Gerontology Series B: Psychological Sciences and Social Sciences 61: S161-9.

Schalk R and Desmette D (2015) Intentions to continue working and its predictors. In: Bal MP, Kooij D and Rousseau DM (eds) Aging Workers and the Employee-Employer Relationship. Cham, Switzerland: Springer International Publishing, 203-20.

Settersten RA (2003) Propositions and controversies in life-course scholarship. In: Settersten RA (ed.) Invitation to the Life Course: Toward New Understanding of Later Life. Amityville, NY: Baywood Publishing Co., 15-48.

Settersten RA and Hagestad GO (1996) What's the latest? II. Cultural age deadlines for educational and work transitions. The Gerontologist 36: 602-13.

Shultz KS (2003) Bridge employment: work after retirement. In: Adams GA and Beehr TA (eds) Retirement: Reasons, Processes, and Results. New York: Springer, 215-41.

Szinovacz ME and DeViney S (2000) Marital characteristics and retirement decisions. Research on Aging 22: 470-98.

TNS Opinion \& Social (2012) Active ageing. Special Eurobarometer 378. Luxembourg: European Commission.

UNESCO (2006) ISCED 1997. International Standard Classification of Education. Montreal: UNESCO Institute for Statistics, 1-49.

Van Dalen HP and Henkens K (2002) Early retirement reform: can it and will it work? Ageing \& Society 22: 209-31.

Van Dalen HP, Henkens K and Schippers J (2010) Productivity of older workers: perceptions of employers and employees. Population and Development Review 36: 309-30.

Wang M (2007) Profiling retirees in the retirement transition and adjustment process: examining the longitudinal change patterns of retirees' psychological well-being. Journal of Applied Psychology 92: 455-74.

Wang M, Zhan Y, Liu S and Shultz KS (2008) Antecedents of bridge employment: a longitudinal investigation. Journal of Applied Psychology 93: 818-30.

Zhan Y and Wang M (2015) Bridge employment: conceptualizations and new directions for future research. In: Bal MP, Kooij D and Rousseau DM (eds) Aging Workers and the EmployeeEmployer Relationship. Cham, Switzerland: Springer, 203-20.

Ellen Dingemans is postdoctoral researcher at the Netherlands Interdisciplinary Demographic Institute (NIDI-KNAW) and she is affiliated to the University Medical Centre Groningen (UMCGRUG). Her dissertation research focused on determinants and consequences of bridge employment in the Netherlands and Europe. Her main research interests include retirement, bridge employment, active ageing and well-being.

Kène Henkens is Head of the Work and Retirement Department of the Netherlands Interdisciplinary Demographic Institute (NIDI-KNAW) and is Professor of Sociology of Retirement at the University of Amsterdam (UvA) and the University Medical Centre Groningen (UMCG-RUG). He has published extensively on issues regarding retirement and the ageing workforce.

Hanna van Solinge is senior researcher at the Netherlands Interdisciplinary Demographic Institute (NIDI-KNAW, RUG). She is particularly interested in the transition from work to retirement in relation to health and well-being. She has published extensively on adjustment to retirement.

\section{Date submitted August 2015 \\ Date accepted July 2016}

